\title{
Chemical and structural analysis of Eucalyptus globulus and E. camaldulensis leaf cuticles: a lipidized cell wall region
}

\section{Paula Guzmán ${ }^{1 *}$, Victoria Fernández ${ }^{1}$ *, José Graça ${ }^{2}$, Vanessa Cabral ${ }^{2}$, Nour Kayali ${ }^{3}$, Mohamed Khayet ${ }^{4}$ and Luis Gil ${ }^{1}$}

${ }^{1}$ Forest Genetics and Ecophysiology Research Group, School of Forest Engineering, Technical University of Madrid, Madrid, Spain

2 Instituto Superior de Agronomia, Centro de Estudos Florestais, Universidade de Lisboa, Lisboa, Portugal

${ }^{3}$ Mass Spectrometry Unit, Faculty of Chemistry, University Complutense of Madrid, Madrid, Spain

${ }^{4}$ Department of Applied Physics I, Faculty of Physics, University Complutense of Madrid, Madrid, Spain

\section{Edited by:}

Anja Geitmann, Université de

Montréal, Canada

Reviewed by:

Mary Lai Preuss, Webster University, USA

Heiner Goldbach, University of Bonn, Germany

\section{*Correspondence:}

Victoria Fernández and Paula Guzmán, Forest Genetics and Ecophysiology Research Group, School of Forest Engineering, Technical University of Madrid, Ciudad Universitaria s/n, Madrid 28040, Spain e-mail:v.fernandez@upm.es; paula.guzman@upm.es
The plant cuticle has traditionally been conceived as an independent hydrophobic layer that covers the external epidermal cell wall. Due to its complexity, the existing relationship between cuticle chemical composition and ultra-structure remains unclear to date. This study aimed to examine the link between chemical composition and structure of isolated, adaxial leaf cuticles of Eucalyptus camaldulensis and E. globulus by the gradual extraction and identification of lipid constituents (cutin and soluble lipids), coupled to spectroscopic and microscopic analyses. The soluble compounds and cutin monomers identified could not be assigned to a concrete internal cuticle ultra-structure. After cutin depolymerization, a cellulose network resembling the cell wall was observed, with different structural patterns in the regions ascribed to the cuticle proper and cuticular layer, respectively. Our results suggest that the current cuticle model should be revised, stressing the presence and major role of cell wall polysaccharides. It is concluded that the cuticle may be interpreted as a modified cell wall region which contains additional lipids. The major heterogeneity of the plant cuticle makes it difficult to establish a direct link between cuticle chemistry and structure with the existing methodologies.

Keywords: cell wall, cuticle, cutin, eucalypt, leaf, lipids, polysaccharides, ultra-structure

\section{INTRODUCTION}

The cuticle is an asymmetric, composite layer covering the surface of most aerial organs of plants (Tyree et al., 1990; Fernández and Brown, 2013), which is mainly extruded into the external wall of epidermal cells (Pollard et al., 2008; Javelle et al., 2010). Due to its location at the interface between the plant and the surrounding environment, the cuticle plays an array of crucial protective and physiological functions (Remus-Emsermann et al., 2011; Serrano et al., 2014). Additionally, it has a role in organ growth and differentiation (Kutschera and Niklas, 2007; Takada and Iida, 2014).

The multi-functional character of the plant cuticle is provided by its complex and heterogeneous chemical and physical nature (Gouret et al., 1993; Guzmán et al., 2014a). From a chemical viewpoint, the cuticle is generally defined as a cutin and/or cutan polymer matrix, with epicuticular waxes deposited on to its outer surface, embedded intracuticular waxes and phenolics, and polysaccharides stemming from the cell wall (Domínguez et al., 2011). Cutin is formed by a network of inter-esterified, hydroxy and hydroxy-epoxy $\mathrm{C}_{16}$ and/or $\mathrm{C}_{18}$ fatty acids (Kolattukudy, 1980), sometimes linked with glycerol (Graça et al., 2002). The chemical composition of an alternative cuticle matrix polymer named cutan remains controversial (Tegelaar et al., 1991; Deshmukh et al., 2005). Cuticular waxes (soluble cuticular lipids) are complex mixtures of aliphatic (mainly long-chain fatty acids, alcohols, alkanes, aldehydes, esters and ketones) and aromatic compounds (Jetter et al., 2006). Polysaccharides present in the cuticle are similar to those found in the cell wall (i.e., cellulose, hemicelluloses and pectins; López-Casado et al., 2007; Guzmán et al., 2014b). Based on the relative abundance of chemical constituents (Schmidt and Schönherr, 1982; Heredia, 2003; Samuels et al., 2008), the cuticle has been conceived as a hydrophobic membrane.

The cuticle has been generally described as having three different layers from the external to the internal surface, i.e.,: (i) the epicuticular wax (EW) layer, (ii) the cuticle proper (CP), and (iii) the cuticular layer (CL; von Mohl, 1847; Jeffree, 2006). It has been traditionally assumed that cutin/cutan and waxes are found both in the CP and CL, while the presence of polysaccharides is restricted to the CL (von Mohl, 1847; Jeffree, 2006). By contrast, the presence of cellulose and pectins in both cuticular layers has been recently reported (Guzmán et al., 2014b). For various species and organs, different patterns of cuticular ultra-structure have been categorized on the basis of transmission electron microscopy (TEM) observations (Holloway, 1982; Jeffree, 2006). However, a fair degree of cuticular structural variation may arise from e.g., the TEM sample preparation procedure implemented as recently shown by Guzmán et al. (2014a).

The cuticular chemical composition and/or ultra-structure of a few organs and species has been studied by gradual extraction 
and analysis of different cuticular fractions (e.g., Fernández et al., 2011, 2014; Tsubaki et al., 2013; Belge etal., 2014), and using diverse microscopic means (e.g., Canet et al., 1996; Casado and Heredia, 2001; Koch etal., 2004). The potential link between chemistry and structure of different cuticular fractions or specific molecular constituents has been examined chiefly focusing on EW (e.g., Baker, 1982; Barthlott et al., 1998; Jeffree, 2006). Integrative studies on the internal cuticle are however, scarce (e.g., Wattendorff and Holloway, 1982; Gouret et al., 1993; Viougeas etal., 1995; Yeats etal., 2012), and the existing relationship between chemical composition and structure remains unclear so far (Khayet and Fernández, 2012). In addition, there is currently a limited understanding of the potential cross-links and/or molecular assemblies taking place between cuticular chemical constituents (Pollard et al., 2008; Kunst and Samuels, 2009).

Given the chemical and physical complexity of the plant cuticle, there is a need for carrying out comprehensive investigations which may help us understand the cuticle in a holistic manner. The high complexity of the cuticle together with an array of technical constrains may lead to theoretical misconceptions concerning the structure, chemistry and function of the cuticle (Guzmán etal., 2014a,b). In this study we aimed at analyzing the link between ultra-structure and chemical composition (focusing on lipids) of the leaf cuticle, following an integrative approach. For this purpose Eucalyptus camaldulensis and E. globulus were used as model species due to their major importance for forestry production (Guzmán et al., 2013). Furthermore, despite such species are native to different habitats their taxonomic proximity may involve a certain degree of cuticular similarity. By merging different analytical and electron microscopy techniques before and after the selective extraction and identification of chemical constituents, the following questions were addressed: (i) is the adaxial leaf cuticle of both species structurally and chemically similar?, (ii) how does the gradual extraction of cuticular components affect cuticular ultra-structure as compared to intact tissues?, and (iii) is it currently possible to establish a relationship between cuticular chemical composition and structure?

\section{MATERIALS AND METHODS \\ PLANT MATERIAL AND CUTICLE ISOLATION}

The adaxial surface of fully expanded, mature, undamaged leaves of E. camaldulensis Dehn and E. globulus Labill was analyzed either intact or after enzymatic isolation of the cuticle. Leaves were collected at late summer from the apex of external, west-facing shoots of 30-35 years old trees growing at the Forest Engineering School Arboretum (Technical University of Madrid, Spain). For each species, 6 and 30 leaves were selected for intact leaf and isolated cuticle analyses, respectively.

Prior to cutting the central part of the leaf blades in small pieces for cuticle isolation, leaf margins and midribs were removed with a scalpel. Leaf cuticles were subsequently isolated in a solution containing 5\% cellulase and 5\% pectinase (Novozymes, Bagsvared, Denmark), plus 1\% polyvinylpyrrolidone (SigmaAldrich, Munich, Germany) and $2 \mathrm{mM}$ sodium azide, which was set to $\mathrm{pH} 5.0$ by adding sodium citrate (Guzmán et al., 2014a). Tissues were maintained in solution (changed after 2 weeks) at room temperature $\left(23-25^{\circ} \mathrm{C}\right)$ for 1 month, manually shaking the flasks at frequent time intervals. After the extraction period, clean intact adaxial cuticles were selected, thoroughly washed in deionized water, air-dried, and stored for further use.

\section{EXTRACTION AND DETERMINATION OF SOLUBLE COMPOUNDS}

Isolated cuticles were cut into small pieces, wrapped in filter paper and successively extracted in $150 \mathrm{~mL}$ of dichloromethane ( 6 h; Sigma-Aldrich), ethanol (12 h; Sigma-Aldrich) and distilled water $(24 \mathrm{~h})$ using a Soxhlet apparatus. Solvents were subsequently evaporated to dryness with a rotary evaporator and the material extracted was weighed and stored. Soxhlet extracted (SE) cuticles were also stored for further analysis.

The cuticular material extracted in dichloromethane was analyzed by gas chromatography-mass spectrometry (GC-MS). Samples were filtered using polytetrafluoroethylene (PTFE) filters prior to injection in a GC-MS apparatus (GC Varian CP-3800 coupled to a MS ion trap Varian Saturn 2200, GC-ITMS, automatic injector COMBI-PAL; CTC Analytics, Zwingen, Switzerland). The chromatographic conditions were as follows ( $86 \mathrm{~min}$ per run): injection volume $1 \mu \mathrm{L}$, with Helium as carrier gas $\left(1.2 \mathrm{~mL} \mathrm{~min}^{-1}\right)$, and injector temperature $290^{\circ} \mathrm{C}$. The column (SLB-5 ms fused silica capillary column, $30 \mathrm{~m} \times 0.25 \mathrm{~mm} \times 0.25 \mu \mathrm{m}$ film thickness; Supelco, Sigma-Aldrich) was set to $40^{\circ} \mathrm{C}$ ( $3 \mathrm{~min}$ ), heating rate of $10^{\circ} \mathrm{C} \mathrm{min} \mathrm{m}^{-1}$ up to $290^{\circ} \mathrm{C}(18 \mathrm{~min})$, and $20^{\circ} \mathrm{C} \mathrm{min}^{-1}$ up to $310^{\circ} \mathrm{C}(13 \mathrm{~min})$. The MS conditions were: $70 \mathrm{eV}$ ionization voltage, $150^{\circ} \mathrm{C}$ trap temperature, $20-550$ units of mass scan range with 8 min solvent delay. The compounds were identified and quantified by comparing their mass spectra with NIST library spectra and analyzing the corresponding peaks of GC-MS ion chromatograms.

\section{EXTRACTION AND DETERMINATION OF CUTIN CONSTITUENTS}

For the two species, $80 \mathrm{mg}$ of dehydrated (oven-dried at $40^{\circ} \mathrm{C}$ before use), SE cuticles were used for cutin depolymerization. Samples were refluxed in $5 \mathrm{~mL}$ of $0.1 \mathrm{M}$ sodium methoxide solution (Sigma-Aldrich) in methanol by heating in an oil bath at $80^{\circ} \mathrm{C}$ for $3 \mathrm{~h}$, and continuous stirring. For separation of de-esterified (filtered) and residual (non-filtered) material from the methanolysis process, mixtures were vacuum filtered using $1 \mu \mathrm{m}$ pore PTFE filters. The residual material was oven-dried under vacuum at $40^{\circ} \mathrm{C}$ overnight, weighted for the determination by mass-loss, of the total content of cuticle de-esterified material (one replicate) and saved for further examination.

The total volume of de-esterified material was divided for glycerol and cutin monomer and precursor identification $(1: 4, \mathrm{v}: \mathrm{v})$, and handled separately. For glycerol analysis, the de-esterified aliquot was sampled as such. For cutin monomer identification, the respective aliquot was acidified to $\mathrm{pH} 6$ with $0.05 \mathrm{M}$ sulfuric acid in methanol, and the solvent was subsequently removed in a rotary evaporator at $50^{\circ} \mathrm{C}$. The obtained residue was partitioned in dichlorometane:water $(1: 1, \mathrm{v}: \mathrm{v} ; 35 \mathrm{~mL}$ each) using a separating funnel. The upper aqueous, clear phase was discarded and the organic, opaque phase located below was partitioned again with the same volume of water.

For GC-MS determination, aliquots $(1 \mathrm{~mL})$ of the de-esterified material and of the accumulated organic phases were collected. 
Aliquots were dried under a $\mathrm{N}_{2}$ flow and derivatized with $\mathrm{N}, \mathrm{O}$ bis(trimethylsilyl)trifluoroacetamide with $1 \%$ trimethylchlorosilane (BSTFA with 1\% TMCS, Sigma-Aldrich) and pyridine at a 1:1 (v:v) ratio. After 15 min staging in an oven at $60^{\circ} \mathrm{C}$, solutions were analyzed with an Agilent 5973 MSD GC-MS (Agilent, Santa Clara, CA, USA) in a DB-5 ms column $(60 \mathrm{~m}$, $0.25 \mathrm{~mm}$ i.e., $0.25 \mu \mathrm{m}$ film thickness; Agilent), with the following GC conditions: injector $320^{\circ} \mathrm{C}$, initial oven temperature $100^{\circ} \mathrm{C}(5 \mathrm{~min})$, heating rate of $8^{\circ} \mathrm{C} \mathrm{min}^{-1}$ up to $250^{\circ} \mathrm{C}$, and $2.5^{\circ} \mathrm{C} \mathrm{min}^{-1}$ up to $320^{\circ} \mathrm{C}(20 \mathrm{~min})$. The $\mathrm{MS}$ conditions were: source $220^{\circ} \mathrm{C}$, quadrupole $150^{\circ} \mathrm{C}$, electron ionization energy $70 \mathrm{eV}$. Cutin monomers were identified by library search (NIST 98, Wiley 6), comparison to standards and/or mass spectra interpretation (Graça et al., 2002). Monomer quantification was calculated from the areas of the corresponding peaks in the CG-MS ion chromatograms. As internal standards for glycerol and cutin monomers, we used 1,12-dodecanediol (0.05-0.3 mg; $\geq 98.5 \%$ GC, Sigma-Aldrich) and methyl 12-hydroxystearate $(0.05-0.1 \mathrm{mg}$; $\geq 99.0 \%$ GC, Sigma-Aldrich), respectively. A response factor of 0.33 in relation to the internal standard $(1,12$-dodecanediol) was used for the quantitation of glycerol. The internal standards were diluted in methanol, homogenized in a warm bath, and added to the de-esterified material before derivatization (Graça and Lamosa, 2010).

\section{ELECTRON MICROSCOPY}

Intact leaves, isolated cuticles, SE cuticles, and the residues obtained after de-esterification of SE cuticles (subsequently called SED residues) were examined by TEM and scanning electron microscopy (SEM).

Gold-sputtered adaxial leaf surfaces and both the inner and outer cuticle and residue surfaces (three replicates per sample) were observed with a Philips XL30 SEM (Eindhoven, The Netherlands) microscope.

For TEM observation, samples were cut into $4 \mathrm{~mm}^{2}$ pieces and fixed in $2.5 \%$ glutaraldehyde-4\% formaldehyde freshly prepared from paraformaldehyde (both from electron microscopy sciences (EMS), Hatfield, PA, USA) for $6 \mathrm{~h}$ at $4^{\circ} \mathrm{C}$, rinsed in ice-cold phosphate buffer, $\mathrm{pH} 7.2$, four times within a period of $6 \mathrm{~h}$ and left overnight. Tissues were post-fixed in a 1:1 $2 \%$ aqueous osmium tetroxide (TAAB Laboratories, Berkshire, UK) and 3\% potassium ferrocyanide (Sigma-Aldrich) solution for $1.5 \mathrm{~h}$. They were then washed with distilled water $(\mathrm{x} 3)$, dehydrated in a graded series of $30,50,70,80,90,95$, and 100\% acetone (x2, 15 min each concentration) and embedded in acetone-Spurr's resin (TAAB Laboratories) solutions [3:1, $2 \mathrm{~h} ; 1: 1,2 \mathrm{~h} ; 1: 3 ; 3 \mathrm{~h}(\mathrm{v}: \mathrm{v})]$ and in pure resin overnight at room temperature $\left(25^{\circ} \mathrm{C}\right)$. Tissues were finally embedded in blocks which were incubated for 3 days at $70^{\circ} \mathrm{C}$. Ultra-thin sections of three leaf and cuticle pieces per treatment were cut, mounted on nickel grids and post-stained with Reynolds lead citrate (EMS) for $5 \mathrm{~min}$. They were subsequently observed with a Jeol 1010 TEM (Tokyo, Japan) operated at $80 \mathrm{kV}$ and equipped with a CCD megaview camera.

The thickness of entire cuticle transversal sections and of the different cuticular regions was measured on TEM micrographs of leaves, intact and SE cuticles, and SED residues using siViewer (Olympus Soft Imaging Solutions, Münster, Germany) and ImageJ 1.45s (National Institutes of Health, Bethesda, MD, USA) softwares. Measurements were performed at periclinal areas, excluding zones located in the vicinity of cuticular pegs, and also the EW layer. Micrographs corresponding to extremely thick or thin cuticle sections or with no clear limits between adjacent cuticular regions were discarded. Finally, 15 micrographs of each sample (corresponding to three $4 \mathrm{~mm}^{2}$ cuticle pieces) were selected for thickness measurement, with 10-20 repetitions.

\section{FOURIER TRANSFORM INFRARED (FTIR) SPECTROSCOPY}

Infrared spectra of cuticle samples (i.e., intact, SE cuticles, and SED residues), were obtained with an attenuated total reflectance (ATR) accessory (MIRacle ATR; PIKE Technologies, Madison, WI, USA) coupled to a FTIR spectrometer (Nicolet Nexus 670-870; Thermo Fisher Scientific, Waltham, MA, USA). Spectra of intact samples were recorded in transmission mode in the range 4000$400 \mathrm{~cm}^{-1}$ with $4 \mathrm{~cm}^{-1}$ resolution and accumulating 64 scans, and analyzed with Omnic v4.1b (Thermo Fisher Scientific) software. Two replicates per sample were analyzed.

\section{RESULTS \\ ELECTRON MICROSCOPY OBSERVATIONS Intact leaves and cuticles}

The adaxial surface of E. camaldulensis and E. globulus leaves and intact cuticles had a rough topography conferred by EW and epidermal structures such as papillae and stomata (Figures 1A-D). The most prominent EW structures were plates with different orientations for E. camaldulensis and tubes for E. globulus. Plates were observed to densely cover the whole leaf and cuticle surfaces with the exception of the tip of some papillae (Figures 1A,C), while wax tubes were principally found around papillae and stomata (Figures 1B,D). The isolated cuticle topography was smoother compared to that of intact leaves, chiefly due to the loss or distortion of some EW during the cuticle isolation process (Figures 1C,D). The cuticle inner sides revealed the epidermal cell surface shape (i.e., the upper periclinal wall with papillae, and the anticlinal flanges or cuticular pegs; Figures 1E,F), and showed a granular pattern especially noticeable in E. globulus (Figure 1F).

The cuticles of E. globulus and E. camaldulensis were between 5.5 to $9.5 \mu \mathrm{m}$ and 2.5 to $5.0 \mu \mathrm{m}$ thick, respectively (Figure 2). The CP of E. camaldulensis (100-250 nm thick; Figure 3A) and E. globulus (350-500 nm thick; Figure 3B) cuticles represented between 5 and $6 \%$ of the total cuticle thickness. The cuticle of $E$. globulus was about two times thicker and had a two to three times thicker CP than E. camaldulensis. The thickness of the EW layer was not considered since the TEM sample preparation procedure may significantly affect EW composition and structure.

In contrast to the EW layer, the remaining cuticular ultrastructure was not significantly altered by the isolation process as derived from comparing intact cuticle TEM micrographs either as isolated tissues or when attached to the leaf. According to the nomenclature suggested by Holloway (1982), the cuticle of both species had a faintly lamellate $\mathrm{CP}$, with alternate electron-lucent and electron-dense lamellae (Figures 3A,B). While the CL of $E$. camaldulensis cuticle showed a gradual decrease of the reticulum toward the $\mathrm{CP}$, an amorphous region could be identified between 


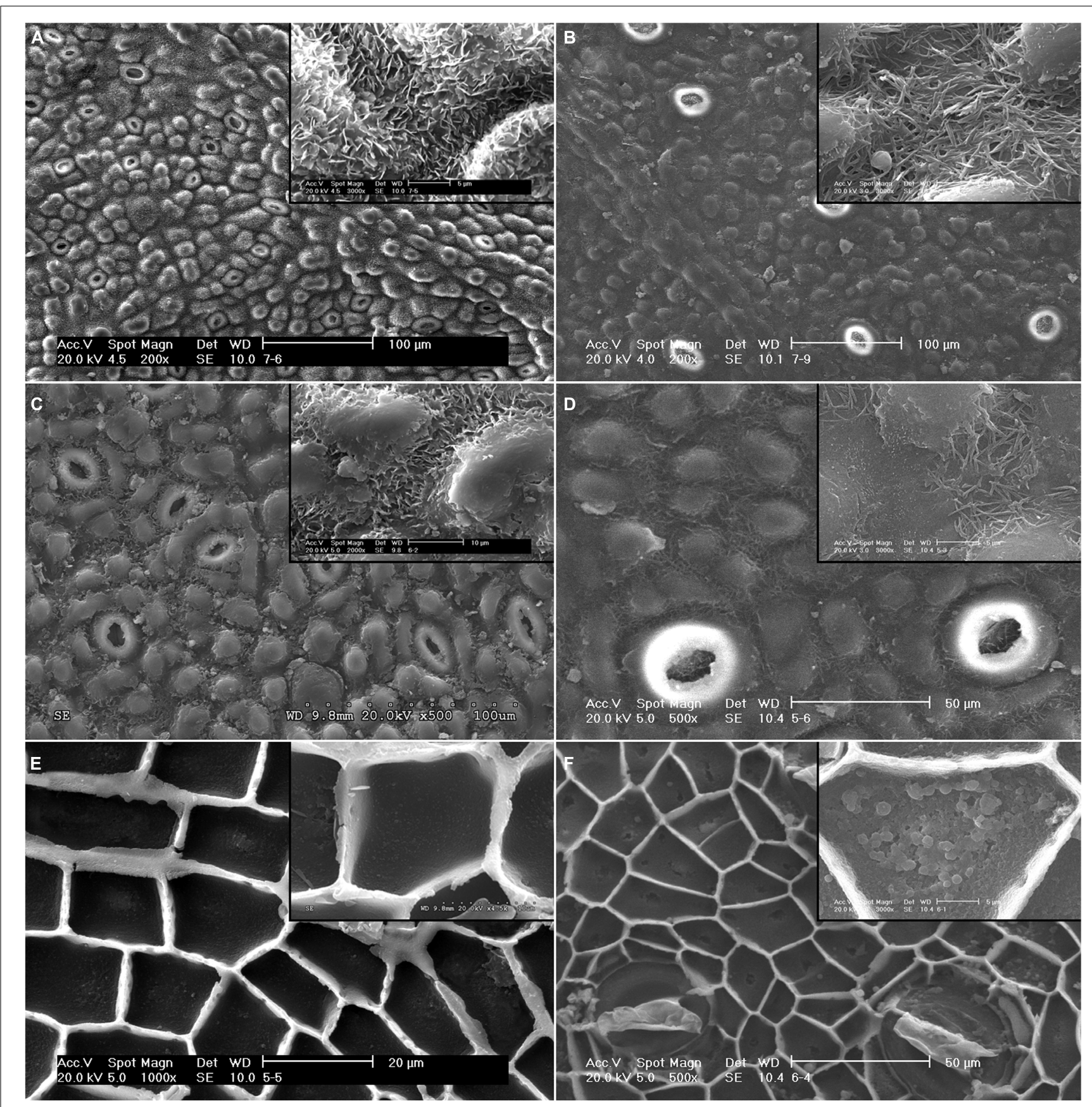

FIGURE 1 | Scanning electron microscopy (SEM) micrographs of the adaxial leaf surface and intact, isolated cuticles of $E$. camaldulensis and $\boldsymbol{E}$. globulus. Surface and detail of EW structures of $E$.

camaldulensis (A) and E. globulus leaves (B). Outer side and detail of
EW structures of E. camaldulensis (C) and E. globulus cuticles (D). Inner side and detail of the granules in the periclinal cuticle of $E$. camaldulensis $(\mathbf{E})$ and $E$. globulus cuticles $(\mathbf{F})$. Bars in insert images: $5 \mu \mathrm{m}(\mathbf{A}, \mathbf{B}, \mathbf{D}, \mathbf{F}), 10 \mu \mathrm{m}(\mathbf{C}, \mathbf{E})$. the $\mathrm{CP}$ and the reticulate inner region in the cuticle of E. globulus. The reticulate and amorphous $\mathrm{CL}$ areas close to the $\mathrm{CP}$ can be respectively, observed in Figures 3A,B.

\section{Soxhlet extracted cuticles}

The topography of the outer surface of SE cuticles became smoother compared to intact tissues (Figures $4 \mathbf{A}, \mathbf{B}$ ). While most of the EW were solubilized, some plates remained in E. camaldulensis SE cuticles (Figure 4A), and a cracked EW layer was observed in E. globulus SE cuticles (Figure 4B). Whilst no major structural changes were noticeable in the inner side of SE cuticles, the granules observed in intact cuticles were mostly removed, and cavities with a similar size were identified in SE periclinal cuticle areas (Figures 4C,D). 


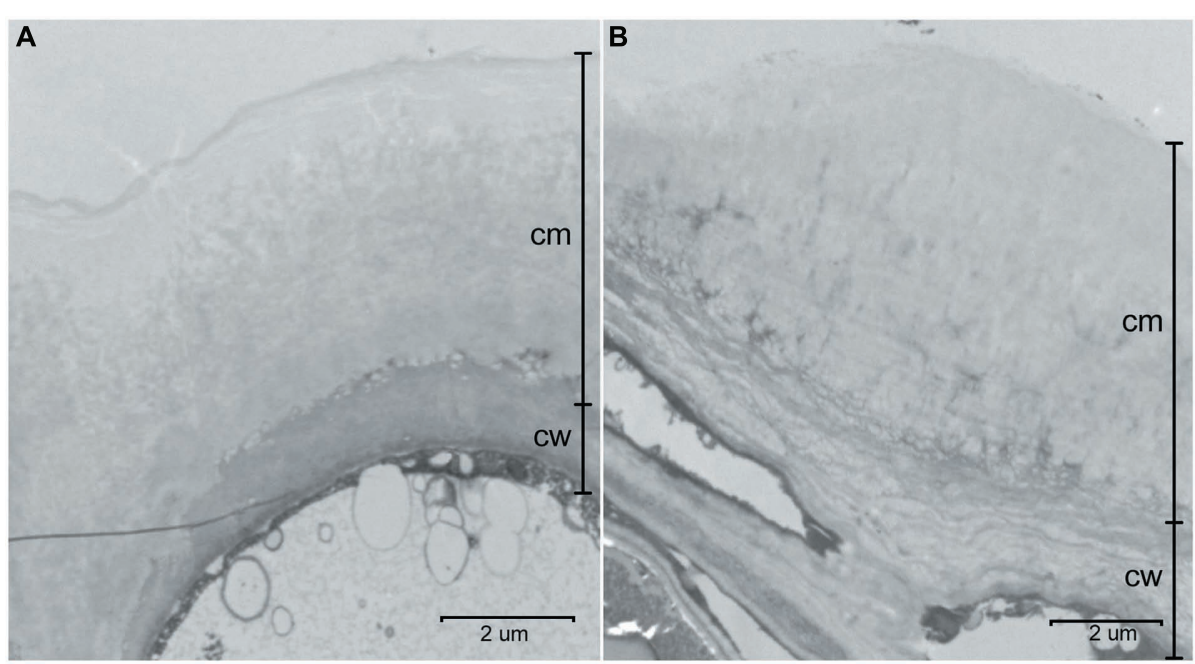

FIGURE 2 | Transversal sections of the adaxial cuticle and outer cell wall of $E$. camaldulensis (A) and $E$. globulus (B) intact leaves. cm: cuticular membrane, cw: cell wall. Bars: $2 \mu \mathrm{m}$.

Patches of EW crystalline projections were also observed in cuticular cross-sections. For both species, the CP lamellae disappeared after Soxhlet extraction. After this process an amorphous, electron-lucent band arose which had a thickness slightly below or within the range of the intact $\mathrm{CP}$. The upper limit of this band was a relatively thin, discontinuous, electron-dense line, which may correspond to non-solubilized waxes (Figures 3C,D). The Soxhlet extraction process did not seem to modify the CL reticulum, and no remarkable structural or thickness changes in the rest of this region were observed (data not shown). The presence of granules in the inner surface of the cuticle was also noticed in TEM micrographs (data not shown).

\section{De-esterified residues}

The structure of SED residues was disrupted as observed in the inner side of such tissues by SEM (Figures $4 \mathrm{E}, \mathrm{F}$ ). The concavity of the periclinal cuticle appeared to increase (e.g., Figure 4E), while the anticlinal cuticle seemed to be more fragile and was not distinguishable in some areas (Figures $4 \mathrm{E}, \mathbf{F}$ ). The upper side of SED residues had a similar appearance to that of SE cuticles (data not shown).

A considerable cuticle thickness decrease of approximately 60 $75 \%$ and $70-80 \%$ for E. camaldulensis and E. globulus cuticles was observed as a result of the de-esterification process (Figures 2 vs. $3 \mathrm{E}, \mathrm{F})$. This reduction largely occurred in association with the inner cuticle part (i.e., the zones which were closer to the epidermal cell walls). This was evidenced by the longer cuticular pegs observed in SED residues as compared to those of intact and SE cuticles (data not shown) and by the presence of EW (e.g., Figures 3E,G).

The cell wall architecture was observed in the transversal sections of SED residues (Figures 3E-H). While diffuse cellulose fibrils were detected in the outermost cuticle region, a lamellate, helicoidal cellulose pattern was noticed in the adjacent inner region. The position within the cuticle of these regions corresponded to that of the CP and CL (Figures 3G,H). The outer, diffuse regions had a thickness similar or sometimes slightly below that of the $\mathrm{CP}$ of intact cuticles, as also recorded for the amorphous outer region of SE cuticles. The cellulose lamellae of the inner region had a mainly parallel orientation to both the periclinal (Figures 3E-H) and the anticlinal cell wall underneath (data not shown), which was especially noticeable in E. camaldulensis SED residues (Figures 3E,G). The electron-dense line located in the EW layer position seemed not to be affected by the de-esterification process, especially in E. camaldulensis (Figures 3E,G). The cellulose fibrils localized in the innermost cuticle areas of SED residues appeared ripped to some extent (e.g., Figure 3F).

\section{Cuticle chemical composition}

The relative proportion of cuticular chemical constituents obtained after successive extractions are shown in Table 1. Both eucalypt species followed a similar trend concerning the relative amount of chemical constituents. The de-esterified material represented the greatest percentage, accounting for approximately half of the total cuticle weight, followed by Soxhlet extracted, soluble compounds. The remaining SED residues (mainly polysaccharides; Figures 5E,F) constituted the smallest cuticular fraction.

The dichloromethane-soluble extractives included aromatic and chiefly aliphatic compounds. Aliphatic molecules accounted for approximately $96 \%$ and $76 \%$ of the total amount of identified compounds for E. camaldulensis and E. globulus cuticles, respectively. The relative amount of aromatics was hence six times greater in E. globulus than in E. camaldulensis. Cyclic compounds (both alicyclics and aromatics) constituted about 39\% (E. camaldulensis) and 76\% (E. globulus). Among E. camaldulensis extractives, the most abundant soluble compound types were aliphatic esters (26\%), followed by primary alcohols (20\%). For E. globulus, terpenes and terpenoids represented the highest percentage of extractives (45\%, chiefly sesqui- and tri-terpenoids), followed by phenolics (21\%). Individually, [(Z)-octadec-9enyl] (Z)-octadec-8-enoate (22\%) and hentetracontan-1-ol (16\%) 


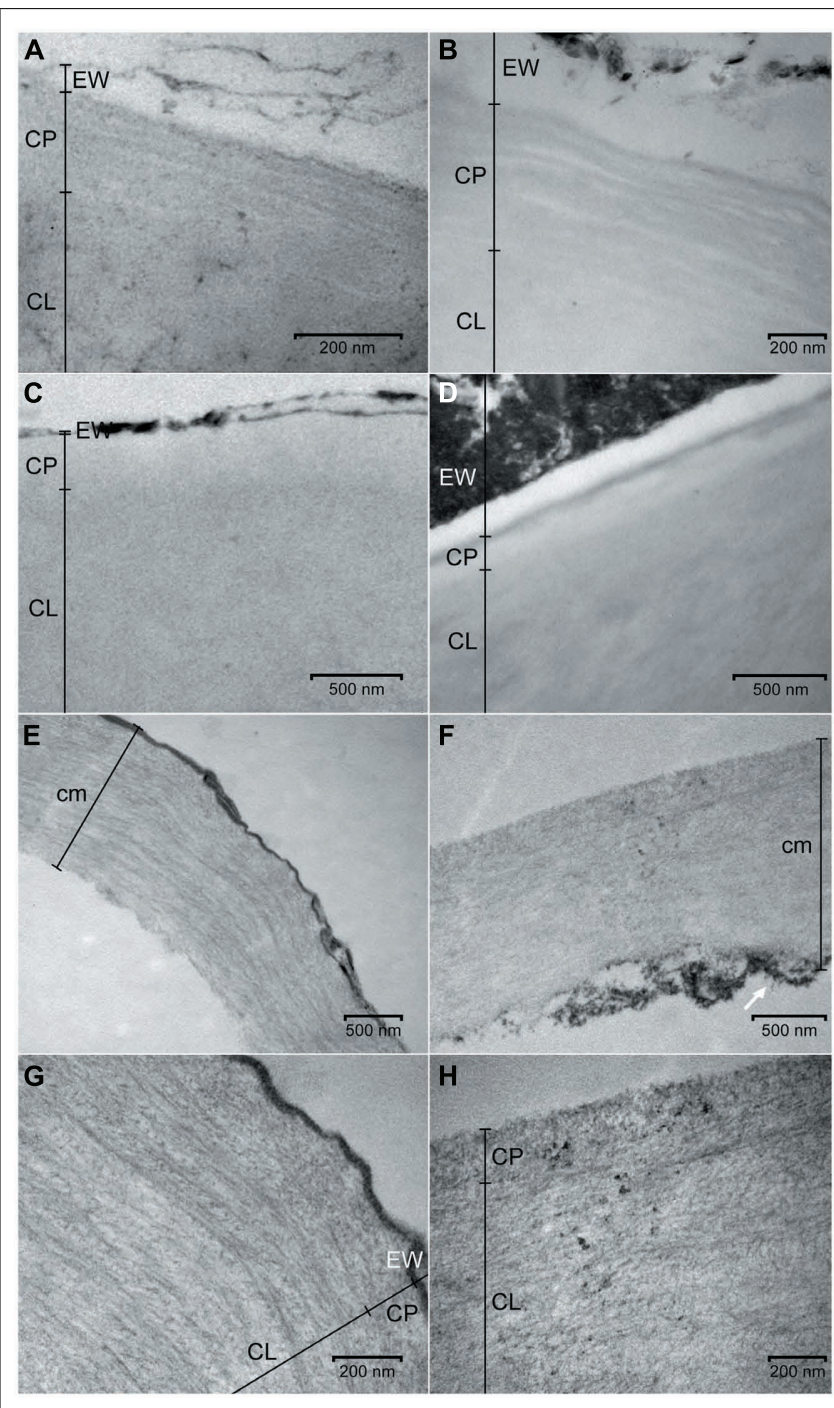

FIGURE 3 | Transmission electron microscopy (TEM) micrographs of the adaxial leaf cuticles of $E$. camaldulensis and $E$. globulus both intact and after successive extractions. Outer regions of $E$. camaldulensis (A) and E. globulus (B) intact cuticles. Outer regions of E. camaldulensis (C) and E. globulus (D) SE cuticles. Complete transversal section and detail of the outer region of $E$. camaldulensis $(\mathbf{E}, \mathbf{G})$ and $E$. globulus $(\mathbf{F}, \mathbf{H})$ SED residue. SE: Soxhlet extracted, SED: Soxhlet extracted, and depolymerized. $\mathrm{CL}$ : cuticular layer; $\mathrm{CP}$ : cuticle proper; $\mathrm{cm}$ : cuticular membrane; EW: epicuticular wax layer. Bars: $200 \mathrm{~nm}$ (A,B,G,H), $500 \mathrm{~nm}$ (C-F). The arrow indicates an area of ripped cellulose fibrils as an example (F).

were the most abundant soluble lipids identified in E. camaldulensis cuticle. (1aR,4R,4aR,7R,7aS,7bS)-1,1,4,7-tetramethyl2,3,4a,5,6,7,7a,7b-octahydro-1aH-cyclopropa[e]azulen-4-ol (16\%) and 5-methoxy-2,2-dimethyl-10-(3-methylbut-2-enyl)pyrano[3,2g]chromen-8-one $(13 \%)$ constituted the highest percentages of soluble extractives for E. globulus cuticle.

For the two species, the lipidic, de-esterified material (Table 2) was found to be chiefly composed of aliphatic $\omega$-hydroxyacids, which represented approximately $62 \%$ (E. camaldulensis) and 69\% (E. globulus) of the total amount of such material (also including unidentified long-chain aliphatic compounds). In both samples $\alpha, \omega$-diacids were also identified and amounted to $17 \%$ (E. camaldulensis) and $8 \%$ (E. globulus). For the two species, the number and total amount of $\mathrm{C}_{18}$ cutin monomers were higher than those of $\mathrm{C}_{16}$ monomers, with $\mathrm{C}_{18} / \mathrm{C}_{16}$ ratios of 1.6 (E. camaldulensis) and 3.1 (E. globulus). Hydroxylated monomers accounted for 76 and $72 \%$ of the total amount of compounds for E. camaldulensis and E. globulus samples. Among them, those having two hydroxyl groups were the most abundant $(42 \%)$ in E. camaldulensis, followed by the identified three-hydroxyl-compound (22\%, Table 2). By contrast, monomers having one hydroxyl group accounted for the greatest percentage (30\%) in E. globulus, closely followed by those having two hydroxyl groups (28\%). On the other hand, epoxy monomers constituted about 13 and $35 \%$ for E. camaldulensis and E. globulus de-esterified material, respectively. The amount of hexadecanoic acid was relatively low as well as that of coumaric acid, the latter being only identified in E. camaldulensis. Although representing a minor contribution, glycerol was present in both samples and its amount was twofold for $E$. camaldulensis.

\section{FTIR spectroscopy}

The ATR-FTIR spectra of intact and SE cuticles, and of SED residues are shown in Figure 5. The spectra of E. camaldulensis and E. globulus intact cuticles (Figures 5A,B) indicate the presence of long-chain linear aliphatic compounds which were associated with the intense and thin bands at 2916 and $2917 \mathrm{~cm}^{-1}$ and at $2849 \mathrm{~cm}^{-1}$ [asymmetric and symmetric vibrations of the methylene groups, $\mathrm{CH}_{2} ; v_{\mathrm{a}}\left(\mathrm{CH}_{2}\right)$ and $v_{\mathrm{s}}\left(\mathrm{CH}_{2}\right)$, respectively], as well as smaller bands at 1462 and $1463 \mathrm{~cm}^{-1}$ and at $719 \mathrm{~cm}^{-1}\left[\mathrm{CH}_{2}\right.$ scissoring and rocking vibrations; $\delta_{\text {scis }}\left(\mathrm{CH}_{2}\right)$ and $\delta_{\text {rock }}\left(\mathrm{CH}_{2}\right)$, respectively]. By comparing the intensities of these bands with those corresponding to the ester groups in the spectra of intact and chiefly SE cuticles (Figures 5C,D), it could be reckoned that these aliphatic compounds are chiefly ascribed to soluble lipids.

The absorptions at 1713 and $1719 \mathrm{~cm}^{-1}$ and their shoulders at 1686 and $1687 \mathrm{~cm}^{-1}[\mathrm{C}=\mathrm{O}$ stretching vibration of the carbonyl bonds; $v(\mathrm{C}=\mathrm{O})]$ for E. camaldulensis and $E$. globulus may correspond to soluble compounds with ketone or aldehyde functional groups which were identified in both samples. These vibrations together with the vibrations at $1168 \mathrm{~cm}^{-1}$ and at 1105 and $1104 \mathrm{~cm}^{-1}$ [asymmetric and symmetric C-O-C stretching vibrations of the ester bonds; $v_{a}(\mathrm{C}-\mathrm{O}-\mathrm{C})_{\text {est }}$ and $v_{\mathrm{s}}(\mathrm{C}-$ $\mathrm{O}-\mathrm{C})_{\text {est }}$, respectively] may also be associated with esterified soluble lipid compounds and especially with the cutin in the polymer form.

The low intensity bands at 1517 and $1518 \mathrm{~cm}^{-1}$ were related to the stretching of aromatic rings $[v(\mathrm{C}-\mathrm{C})$ conjugated with $(\mathrm{C}=\mathrm{C})$ or $v(\mathrm{C}-\mathrm{C}) /(\mathrm{C}=\mathrm{C})]$. The middle intensity bands at 1030 and $1035 \mathrm{~cm}^{-1}$ were assigned to glycosidic bonds typical of polysaccharides $\left[v(\mathrm{C}-\mathrm{O}-\mathrm{C})_{\mathrm{gly}}\right]$. The broad bands appearing at 3388 and $3345 \mathrm{~cm}^{-1}$ [H-bonded, O-H stretching vibration; $v(\mathrm{O}-\mathrm{H} \cdots \mathrm{O})$ ] were assigned to hydroxyl functional groups and could be related to tissue hydration. The assignment of other minor bands can be found in Heredia-Guerrero et al. (2014).

The spectra of SE cuticles (Figures 5C,D) showed an increment in the bands associated with ester functional groups. By 

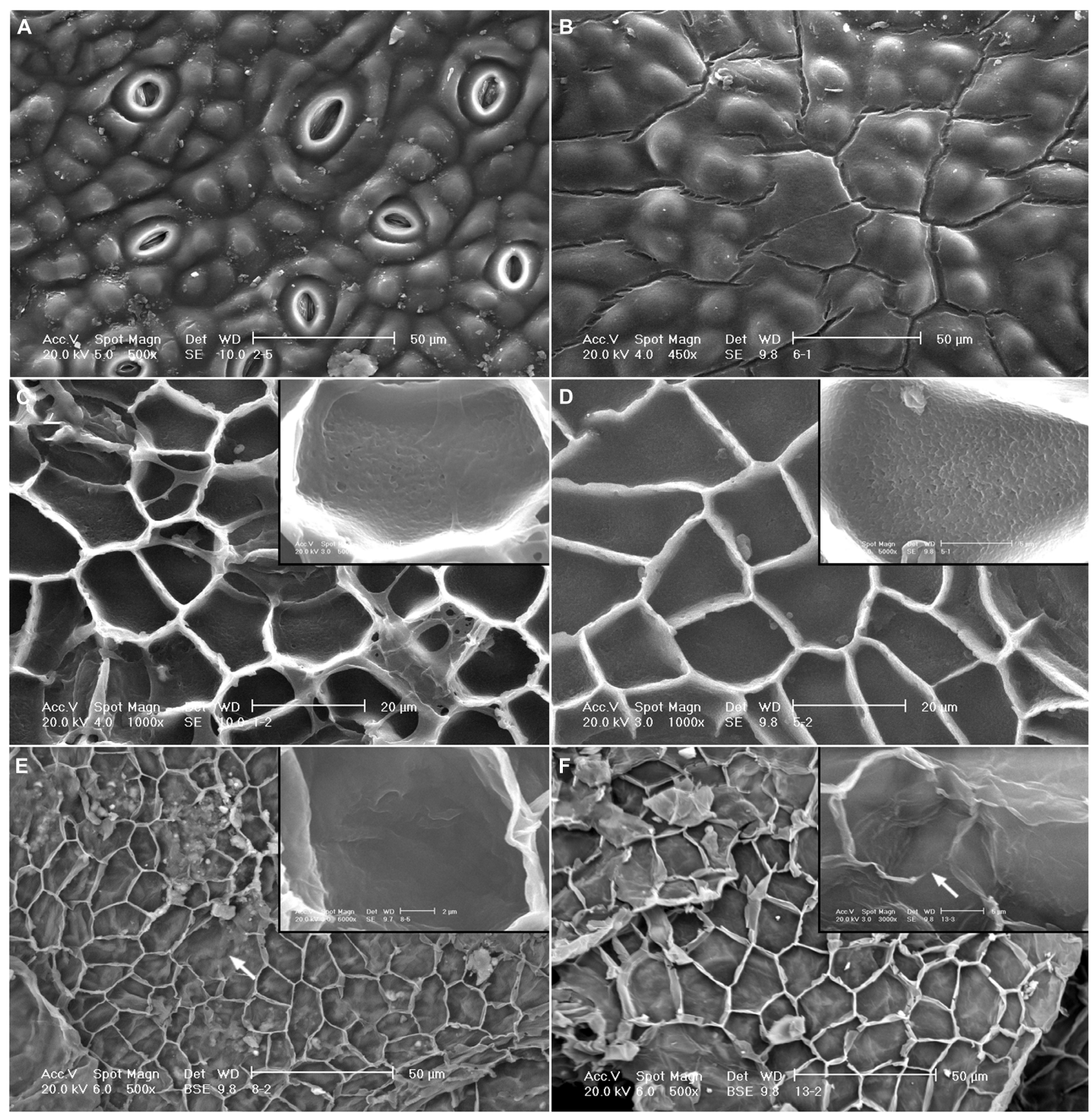

FIGURE 4 | SEM micrographs of the adaxial leaf cuticles of $E$. camaldulensis and $E$. globulus after successive extractions. Outer side of E. camaldulensis (A) and E. globulus (B) SE cuticles. Inner side and detail of E. camaldulensis (C) and E. globulus (D) SE cuticles. Inner side and detail of
E. camaldulensis (E) and E. globulus (F) SED residues. SE: Soxhlet extracted, SED: Soxhlet extracted, and depolymerized. Bars in insert images: $5 \mu \mathrm{m}$ (C,D,F), $2 \mu \mathrm{m}$ (E). Arrows indicate areas were the anticlinal cuticle was not visible $(\mathbf{E}, \mathbf{F})$. comparing the intensity of the bands corresponding to the asymmetric and symmetric vibrations of $\mathrm{CH}_{2}$ and that of the ester $\mathrm{C}-\mathrm{O}$ stretching vibration, it can be concluded that most of the $\mathrm{CH}_{2}$ can be assigned to cutin. The higher intensity of the bands associated with aromatic compounds in SE cuticles spectra as compared to those observed in the spectra of intact cuticles indicated the presence of aromatic compounds related to insoluble lipids and phenolics.

Finally, the spectra of SED residues (Figures 5E,F) exhibited an increase of the bands assigned to polysaccharides. In addition, the broad bands corresponding to hydroxyl groups increased with respect to the intact and SE cuticle spectra, and may correspond to hydrated polysaccharides. On the other hand, the spectra of E. globulus SED residue still showed the presence of a relatively minor amount of non-solubilized long-chain aliphatic compounds (Figure 5F), which constitute the most noticeable difference between the two species as derived from all the spectra analyzed.

\section{DISCUSSION}

In this study, we analyzed the chemical composition of the adaxial leaf cuticle of E. camaldulensis and E. globulus in relation to their ultra-structure, by merging different analytical and microscopic methods. Such species were selected as model due to their 
Table 1 | Chemical composition of adaxial cuticles of Eucalyptus camaldulensis and $E$. globulus leaves after successive extractions expressed as weight percentages of the intact cuticles.

\begin{tabular}{|c|c|c|c|}
\hline \multirow[t]{2}{*}{ Sample } & \multirow{2}{*}{$\begin{array}{l}\text { Soxhlet } \\
\text { extractives (\%) }\end{array}$} & \multicolumn{2}{|c|}{ SE cuticle } \\
\hline & & $\begin{array}{l}\text { De-esterified } \\
\text { material (\%) }\end{array}$ & $\begin{array}{l}\text { Residual material } \\
\text { (SED residue; \%) }\end{array}$ \\
\hline E. camaldulensis & 38.3 & 48.2 & 13.5 \\
\hline E. globulus & 37.3 & 53.6 & 9.1 \\
\hline
\end{tabular}

SE, Soxhlet extracted; SED, Soxhlet extracted and depolymerized.

commercial significance for forestry production. Since they belong to the same genus, such leaf cuticles may additionally have chemical and structural similarities which may however, be affected by their different native habitat. Only few studies analyzed plant cuticles following an integrative approach, and the link between cuticle chemistry and structure remains unclear. On the other hand, the presence and role of cuticular polysaccharides has been taken into account only in few investigations (e.g., Matas et al., 2004; López-Casado et al., 2007; España et al., 2014; Guzmán et al., 2014b).

\section{CUTICLE CHEMICAL COMPOSITION}

According to the assignment of cuticular fractions after successive chemical extractions, cutin (directly associated with de-esterified material; e.g., España et al., 2014) was the most abundant component for the two eucalypt samples analyzed, accounting for $48-54 \%$ of the total cuticle weight, followed by soluble lipids (organic solvent extractives; about 38-37\%). Polysaccharides actually represented the lowest cuticle fraction (the residual material; 14.9\%).

Nevertheless, the different cuticle extraction processes may lead to significant chemical losses and to a potentially inaccurate assignment of chemical groups. For example, it is likely that the polysaccharide fraction is currently underestimated, in contrast to the possibly overestimated cutin fraction. The de-esterification process may have released additional chemical constituents which are linked by ester bonds (e.g., waxes, phenolics, pectins, or

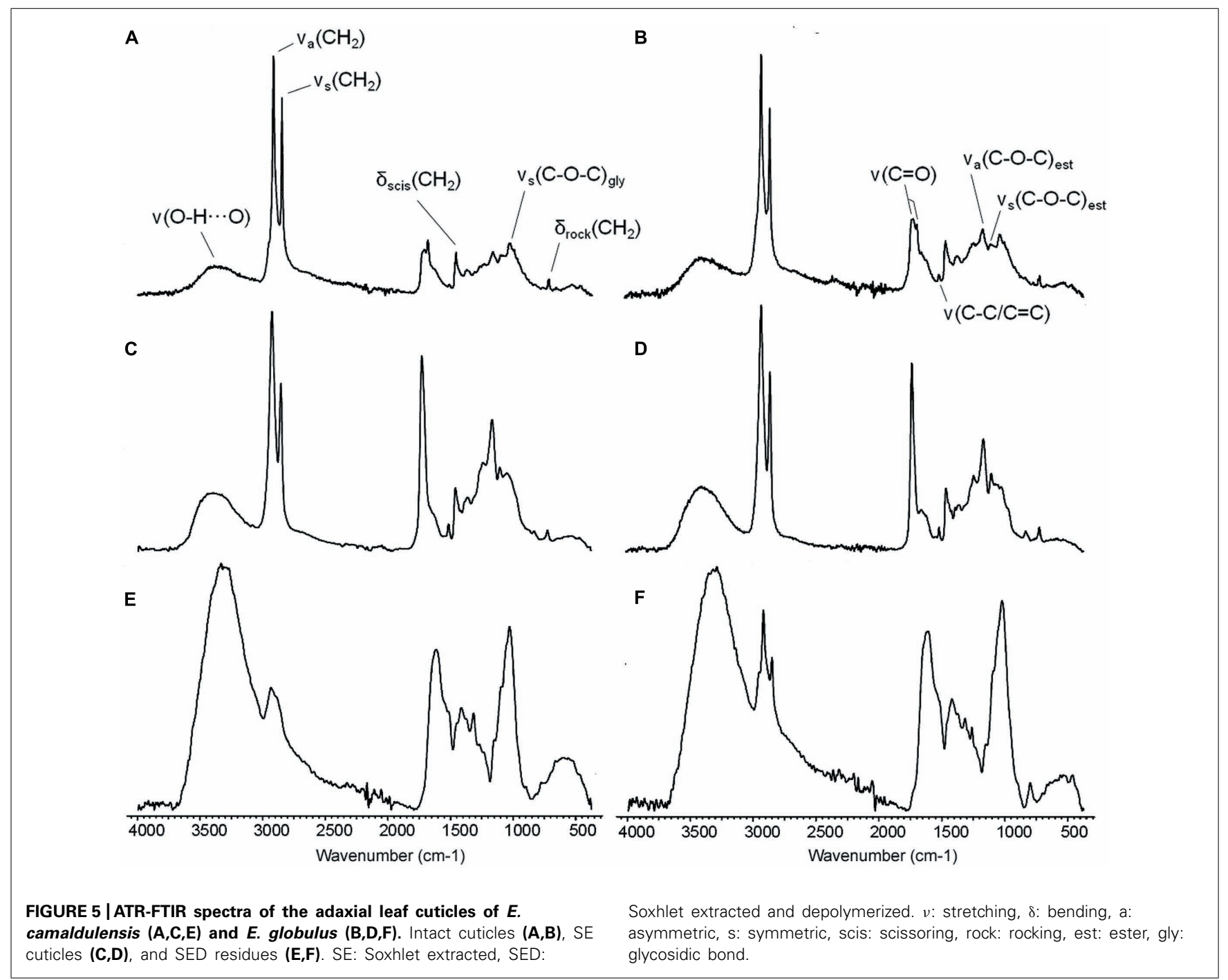


Table 2 | Cutin composition of isolated adaxial cuticles of E. camaldulensis and E. globulus leaves.

\begin{tabular}{|c|c|c|}
\hline \multirow[b]{2}{*}{ Cutin components } & \multicolumn{2}{|c|}{ Relative abundance (\%) } \\
\hline & E. camaldulensis & E. globulus \\
\hline 16-Hydrohexadecanoic acid & 2.4 & 1.3 \\
\hline $\begin{array}{l}\text { 9(7-10), 16-Dihydroxyhexadecanoic } \\
\text { acid }\end{array}$ & 28.1 & 17.6 \\
\hline 9(10),18-Dihydroxyoctadecenoic acid ${ }^{1}$ & 0.0 & 5.1 \\
\hline 9-Epoxy-18-hydroxyoctadecanoic acid & 9.5 & 28.6 \\
\hline 9-Epoxy-octadecane-1,18-dioic acid & 3.0 & 4.8 \\
\hline $\begin{array}{l}\text { 9,10-Dihydroxyoctadecane-1,18-dioic } \\
\text { acid }\end{array}$ & 14.0 & 3.3 \\
\hline $\begin{array}{l}\text { Epoxy-9(10),18-dihydroxyoctadecanoic } \\
\text { acid }^{2}\end{array}$ & 0.0 & 1.7 \\
\hline $9,10,18$-Trihydroxyoctadecanoic acid & 22.0 & 14.4 \\
\hline Coumaric acid & 0.6 & 0.0 \\
\hline Hexadecanoic acid & 0.4 & 0.2 \\
\hline Glycerol & 4.4 & 2.4 \\
\hline Unidentified $^{3}$ & 15.6 & 20.6 \\
\hline
\end{tabular}

${ }^{1}$ Position of double bond not assigned

2 Position of epoxide not assigned

${ }^{3}$ Several long-chain aliphatic compounds

hemicelluloses), trapped in or strongly bound to cutin and/or polysaccharide networks. The constituents located in the inner cuticle regions were especially affected, as concluded from the estimated thickness loss and occurrence of ripped cellulose fibrils in SED residues. Furthermore, significant amounts of pectins, hemicelluloses, mineral elements and even cellulose may be lost when keeping tissues in aqueous solution, e.g., during the cuticle isolation, Soxhlet extraction, or de-esterification processes. A number of factors associated with e.g., the cuticle isolation process, solubility of different lipid types in organic solvents, and/or physical constraints that may limit the access of the solvents and solutes employed for lipid extraction and cutin depolymerization, can ultimately influence the gross amount, quality and structure of cuticular components.

Some of the Soxhlet extracted compounds identified in this study have been previously reported for E. camaldulensis and E. globulus (e.g., Li et al., 1997; Silvestre et al., 1997; Jeffree, 2006; Steinbauer et al., 2009; Verdeguer et al., 2009). Differences in relation to the occurrence and relative content of molecular constituents and soluble compound types were observed between the two species. Aliphatic esters (26\%) and terpenes and terpenoids (45\%) were the most abundant compounds in E. camaldulensis and E. globulus cuticles, respectively. The amount of cyclic compounds was almost twofold higher for E. globulus as compared to E. camaldulensis ( 76 vs. $39 \%$ ), with aromatics being six times more abundant in E. globulus (24 vs. 4\%).

The dissimilar cutin monomer composition of the two eucalypt species analyzed may lead to different cutin molecular architectures (Graça and Lamosa, 2010). This was however, not noticeable in terms of different TEM cuticular ultra-structures. E. camaldulensis had a higher proportion of $\mathrm{C}_{18}$ chain-length monomers as compared to E. globulus $\left(\mathrm{C}_{18} / \mathrm{C}_{16}\right.$ ratio of 3.1 vs. 1.6, respectively). Additionally, E. camaldulensis had higher occurrence of monomers with mid-chain hydroxyl groups and a higher relative content of $\alpha, \omega$-diacids $(17.0 \%$ vs. $8.1 \%)$ and glycerol $(4.4 \%$ vs. $2.4 \%)$. The cuticle composition differences recorded may lead to structural differences concerning e.g., the degree of reticulation or molecular arrangement, also considering the occurrence of higher glycerol and $\alpha, \omega$-diacids amounts in E. camaldulensis, as observed in suberins (Graça et al., 2002; Graça and Lamosa, 2010).

\section{INTACT CUTICLE ULTRA-STRUCTURE}

The ultra-structure of E. camaldulensis and E. globulus cuticles is characterized by having an EW layer with different crystalline projections (plates and tubes, respectively), a faintly lamellate $\mathrm{CP}$ and a CL with variable morphology. A fully reticulate $C L$ was observed in E. camaldulensis cuticle, whereas an external amorphous $C L$ was found between the $\mathrm{CP}$ and the reticulate internal CL of E. globulus. Intact cuticle inner surfaces were additionally covered with granular structures. The occurrence of a bi-layered CL, as observed for $E$. globulus, has been shown in other young and mature leaf cuticles of different species (e.g., Schmidt and Schönherr, 1982; Wattendorff and Holloway, 1982; Jeffree, 2006). The presence of granules in the inner surface of isolated leaf cuticles has been previously reported (Oladele, 1983; Carpenter et al., 2007).

In this study, we found inter-specific differences in relation to the thickness, ultra-structure, and chiefly chemical composition of the two eucalypt cuticles analyzed. Such cuticle variations may be associated with genetic traits having an adaptive function in response to their native environment (leaves of a similar age were collected from E. camaldulensis and E. globulus trees grown under similar environmental conditions). Cuticular differences between species belonging the same genus have been previously reported with especial focus on EW (e.g., Hallam and Chambers, 1970; Riedel et al., 2007).

\section{ASSESSING THE LINK BETWEEN CUTICULAR CHEMISTRY AND ULTRA-STRUCTURE SOXHLET EXTRACTED CUTICLES}

The lamellate $\mathrm{CP}$ regions observed in intact leaf cuticles were replaced by amorphous, electron-lucent bands after Soxhlet extraction. These bands had a thickness in the same range or slightly below that of the corresponding intact $\mathrm{CP}$. By contrast, no remarkable changes were noticed between the CL of intact and SE cuticles. X-ray diffraction and TEM studies performed on Hedera helix leaf cuticles both intact and after solvent extraction revealed similar results, suggesting an intermolecular disorganization of the cuticles, particularly in the $\mathrm{CP}$ (Viougeas etal., 1995). The appearance of the CL was also preserved (Viougeas et al., 1995), alike in Agave americana extracted cuticles (Wattendorff and Holloway, 1982). The CP thickness variation may be due to several phenomena which may also affect the CL region, such as the loss of cuticular material and structure, or the potential shrinkage of the tissues as affected by Soxhlet extraction 
or TEM sample preparation procedures. The influence of cuticle position within one or between different leaves should also be considered (Riederer and Schönherr, 1988).

No clear relationship between soluble lipids composition and cuticle internal morphology could be established. As an exception, E. camaldulensis epicuticular plates may correspond to hentetracontan-1-ol (Jeffree, 2006). The chemical nature of the CP lamellae has been attempted to be identified in a few investigations (see Jeffree, 2006), but remains unclear so far. Our results indicate that the electron-lucent lamellae of E. camaldulensis and E. globulus CP are partially composed of soluble lipids as suggested by Domínguez and Heredia (1999) for the Clivia miniata leaf cuticle, but the presence of other free or chemically bound compounds cannot be discarded. The granular structures covering the inner, intact cuticle surface which were removed during Soxhlet extraction may be associated with soluble intracuticular lipids. The remaining granules may correspond to insoluble lipids and/or cutin (i.e., cutinsomes; Heredia-Guerrero et al., 2008).

\section{DE-ESTERIFIED RESIDUES}

The de-esterification step led to substantial structural changes as compared to the Soxhlet extraction process. While FTIR spectra confirmed the major polysaccharide nature of the SED residues (Heredia-Guerrero et al., 2014), TEM micrographs enabled us to observe the cellulose architecture of the external cell wall, with a non-ordered, outer region and a larger multi-layered, helicoidal inner region (also visible in cuticular pegs). The relative position within the cuticles and measurement of TEM micrographs of intact, SE cuticles and such SED residues indicate that these regions may be ascribed to the $\mathrm{CP}$ and the $\mathrm{CL}$, respectively.

One or the two cellulose fibril orientation patterns found in the SED residues have been previously reported for the epidermal cell wall of a few species and organs (e.g., Roland et al., 1982; Kutschera, 2008), and also for the H. helix leaf cuticle (Canet et al., 1996). Thereby, the structure of the cellulose network seems to leave an imprint on the morphology of cuticular cross-sections and may contribute to the different ultra-structure of the $\mathrm{CP}$ (possibly with randomly oriented cellulose) and CL (with ordered cellulose). However, it is also possible that the removal of cuticular material may have disrupted the orientation and arrangement of the cellulose network. Other factors should be also taken into account, such as those affecting SE cuticles.

Together with cellulose, it is likely that other cuticular polysaccharides, such as pectins or hemicelluloses, extend throughout the cuticle, as derived from cellulose and pectin distribution in intact leaf cuticles of three model species (Guzmán et al., 2014b). Under certain conditions, these polysaccharides might form a gel-like phase with embedded cellulose fibrils, as described for plant cell walls (Cosgrove, 2005; Burton et al., 2010). By analogy with the cell wall, the cellulose fibrils may constitute the reinforcing rods of the cuticle, while the noncellulosic phase may provide flexibility, mechanical support (Burton et al., 2010), and facilitate the transport of hydrophilic, polar compounds and water through the cuticle (Guzmán et al., 2014a,b).
A significant amount of material was removed largely from the inner cuticle region, which experienced a thickness reduction of approximately $60-80 \%$. Working with A. americana leaf cuticles, Wattendorff and Holloway (1982) reported a thickness reduction of $40 \%$ or more from the inner side after cutin depolymerization. Apart from the lower content and/or degree of polymerization of cutin located in the more exposed internal CL, which may yield this region more susceptible to degradation (Wattendorff and Holloway, 1982), the role of further chemical compounds should also be considered as discussed above.

\section{IMPLICATIONS OF THE RESULTS OBTAINED}

The chemical and structural analyses performed with E. globulus and E. camaldulensis leaves, indicate that the cuticle of such species may be interpreted as a lipidized cell wall region. This result is in agreement with the viewpoint of Yeats and Rose (2013), who suggested that the cuticle can be considered a specialized lipidic modification of the cell wall. Our results show that a polysaccharide network may provide the basis for cuticle structure, a role which has been frequently assigned almost exclusively to cutin (Kolattukudy, 1970). Cuticular lipid constituents may impregnate and be intruded into such cell wall matrix, with waxes being also deposited on to the outer cuticle surface, early at epidermal cell ontogeny (Jeffree, 2006; Guzmán et al., 2014b). The occurrence of a polysaccharide network throughout the entire cuticle, with the exception of the EW layer, may have significant bio-mechanical implications and also contribute to the multi-directional transport of water and solutes as suggested by Guzmán et al. (2014a,b).

It is likely that the actual proportion of polysaccharides is seriously underestimated by current methods of cuticular handling and analysis. The importance of polysaccharides as integral, essential cuticle materials should be recognized for the development of methodologies which allow a proper interpretation of the plant cuticle in biological, chemical, and physical terms. In light of the present study, the prevailing model which conceives the cuticle as a lipidic and hydrophobic extra-cellular layer should be reconsidered, highlighting its cell wall nature and heterogeneous character in terms of polarity/apolarity and hydrophobicity/hydrophilicity. However, further studies with different plant organs, organ parts, and species will be required for proposing a broader plant cuticle model, and also for establishing a link between cuticle chemistry, structure, and function under an ecophysiological perspective.

While no specific cuticle structural patterns could be identified in association with chemical composition, the background cell wall architecture seems to have an effect on cuticle morphology. We hence conclude that the existing methodologies do not fully enable to establish a direct link between cuticle composition and structure. Therefore, the implementation of new experimental approaches also analyzing the performance of pure chemical compounds (e.g., cutin monomers) may help us elucidate the link between cuticle structure and chemistry also in relation with different plant species, organs, and habitats.

\section{ACKNOWLEDGMENTS}

The authors are grateful to Dr. Armando J. D. Silvestre (University of Aveiro, Portugal) and Dr. M. Amparo Blázquez (University of Valencia, Spain) for providing information about eucalypt 
soluble lipids and to Ramiro Martínez (Novozymes) for facilitating free enzyme samples. We also wish to thank M. Paz Andrés, Dr. Carlos Arrabal and Cristina Gutiérrez (Complutense University of Madrid, Spain) for technical assistance with soluble lipid extraction and analysis. Thanks to Dr. J. A. Heredia-Guerrero for revising the FTIR spectroscopy results. Paula Guzmán is supported by a pre-doctoral grant from the Technical University of Madrid. Victoria Fernández is supported by a Ramón y Cajal contract (MINECO, Spain), co-financed by the European Social Fund.

\section{REFERENCES}

Baker, E. A. (1982). “Chemistry and morphology of plant epicuticular waxes," in The Plant Cuticle, Linnean Society Symposium Series, Vol. 10, eds D. F. Cutler, K. L. Alvin, and C. E. Price (London, UK: Academic Press), 139-165.

Barthlott, W., Neinhuis, C., Cutler, D., Ditsch, F., Meusel, I., Theisen, I., et al. (1998). Classification and terminology of plant epicuticular waxes. Bot. J. Linn. Soc. 126, 237-260. doi: 10.1111/j.1095-8339.1998. tb02529.x

Belge, B., Llovera, M., Comabella, E., Graell, J., and Lara, I. (2014). Fruit cuticle composition of a melting and a nonmelting peach cultivar. J. Agric. Food Chem. 62, 3488-3495. doi: 10.1021/jf5003528

Burton, R. A., Gidley, M. J., and Fincher, G. B. (2010). Heterogeneity in the chemistry, structure and function of plant cell walls. Nat. Chem. Biol. 6, 724-732. doi 10.1038/nchembio.439

Canet, D., Rohr, R., Chamel, A., and Guillain, F. (1996). Atomic force microscopy study of isolated ivy leaf cuticles observed directly and after embedding in Epon ${ }^{\circledR}$. New Phytol. 134, 571-577. doi: 10.1111/j.1469-8137.1996. tb04922.x

Carpenter, R. J., Jordan, G. J., Leigh, A., and Brodribb, T. J. (2007). Giant cuticular pores in Eidothea zoexylocarya (Proteaceae) leaves. Am. J. Bot. 94, 1282-1288. doi 10.3732/ajb.94.8.1282

Casado, C. G., and Heredia, A. (2001). Ultrastructure of the cuticle during growth of the grape berry (Vitis vinifera L.). Physiol. Plant. 111, 220-224. doi: 10.1034/j.1399-3054.2001.1110213.x

Cosgrove, D. J. (2005). Growth of the plant cell wall. Nat. Rev. Mol. Cell Biol. 6 , 850-861. doi: 10.1038/nrm1746

Deshmukh, A. P., Simpson, A. J., Hadad, C. M., and Hatcher, P. G. (2005) Insights into the structure of cutin and cutan from Agave americana leaf cuticle using HRMAS NMR spectroscopy. Org. Geochem. 36, 1072-1085. doi 10.1016/j.orggeochem.2005.02.005

Domínguez, E., and Heredia, A. (1999). Self-assembly in plant barrier biopolymers. Z. Naturforsch. 54, 141-143.

Domínguez, E., Heredia-Guerrero, J. A., and Heredia, A. (2011). The biophysical design of plant cuticles: an overview. New Phytol. 189, 938-949. doi: 10.1111/j.1469-8137.2010.03553.x

España, L., Heredia-Guerrero, J. A., Segado, P., Benítez, J. J., Heredia, A., and Domínguez, E. (2014). Biomechanical properties of the tomato (Solanum lycopersicum) fruit cuticle during development are modulated by changes in the relative amounts of its components. New Phytol. 202, 790-802. doi: 10.1111/nph. 12727

Fernández, V., and Brown, P. H. (2013). From plant surface to plant metabolism: the uncertain fate of foliar-applied nutrients. Front. Plant Sci. 4:289. doi: 10.3389/fpls.2013.00289

Fernández, V., Khayet, M., Montero-Prado, P., Heredia-Guerrero, J. A., Liakopoulos, G., Karabourniotis, G., et al. (2011). New insights into the properties of pubescent surfaces: peach fruit as a model. Plant Physiol. 156, 2098-2108. doi: 10.1104/pp.111.176305

Fernández, V., Sancho-Knapik, D., Guzmán, P., Peguero-Pina, J. J., Gil, L., Karabourniotis, G., et al. (2014). Wettability, polarity and water absorption of holm oak leaves: effect of leaf side and age. Plant Physiol. 166, 168-180. doi: 10.1104/pp.114.242040

Gouret, E., Rohr, R., and Chamel, A. (1993). Ultrastructure and chemical composition of some isolated plant cuticles in relation to their permeability to the herbicide diuron. New Phytol. 124, 423-431. doi: 10.1111/j.14698137.1993.tb03832.x
Graça, J., and Lamosa, P. (2010). Linear and branched poly( $\omega$-hydroxyacid) esters in plant cutins. J. Agric. Food Chem. 58, 9666-9674. doi: 10.1021/jf1015297

Graça, J., Schreiber, L., Rodrigues, J., and Pereira, H. (2002). Glycerol and glyceryl esters of $\omega$-hydroxyacids in cutins. Phytochemistry 61, 205-215. doi: 10.1016/S0031-9422(02)00212-1

Guzmán, P., Fernández, V., Khayet, M., García, M. L., Fernández, A., and Gil, L. (2014a). Ultrastructure of plant leaf cuticles in relation to sample preparation as observed by transmission electron microscopy. Scientific World J. 963921:9. doi: 10.1155/2014/963921

Guzmán, P., Fernández, V., García, M. L., Khayet, M., Fernández, A., and Gil, L. (2014b). Localization of polysaccharides in isolated and intact cuticles of eucalypt, poplar and pear leaves by enzyme-gold labelling. Plant Physiol. Biochem. 76, 1-6. doi: 10.1016/j.plaphy.2013.12.023

Guzmán, P., Gil, L., and Tadesse, W. (2013). Variation in growth traits and survival of landraces of Eucalyptus globulus Labill in the Ethiopian highlands. Forest Syst. 22, 401-407. doi: 10.5424/fs/2013223-04130

Hallam, N. D., and Chambers, T. C. (1970). The leaf waxes of the genus Eucalyptus L'Heritier. Aust. J. Bot. 18, 335-386. doi: 10.1071/BT9700335

Heredia, A. (2003). Biophysical and biochemical characteristics of cutin, a plant barrier biopolymer. Biochim. Biophys. Acta 1620, 1-7. doi: 10.1016/S03044165(02)00510-X

Heredia-Guerrero, J. A., Benítez, J. J., Domínguez, E., Bayer, I. S., Cingolani, R., Athanassiou, A., et al. (2014). Infrared and Raman spectroscopic features of plant cuticles: a review. Front. Plant Sci. 5:305. doi: 10.3389/fpls.2014. 00305

Heredia-Guerrero, J. A., Benítez, J. J., and Heredia, A. (2008). Self-assembled polyhydroxy fatty acids vesicles: a mechanism for plant cutin synthesis. Bioessays 30, 273-277. doi: 10.1002/bies.20716

Holloway, P. J. (1982). "Structure and histochemistry of plant cuticular membrane: an overview," in The Plant Cuticle, Linnean Society Symposium Series, Vol. 10, eds D. F. Cutler, K. L. Alvin, and C. E. Price (London, UK: Academic Press), 1-32.

Javelle, M., Vernoud, V., Rogowsky, P. M., and Gwyneth, C. I. (2010). Epidermis: the formation and functions of a fundamental plant tissue. New Phytol. 189, 17-39. doi: 10.1111/j.1469-8137.2010.03514.x

Jeffree, C. E. (2006). “The fine structure of the plant cuticle," in Biology of the Plant Cuticle, Annual Plant Reviews, Vol. 23, eds M. Riederer and C Müller (Oxford, UK: Blackwell), 11-125. x

Jetter, R., Kunst, L., and Samuels, A. L. (2006). "Composition of plant cuticular waxes," in Biology of the Plant Cuticle, Annual Plant Reviews, Vol. 23, eds M. Riederer and C Müller (Oxford, UK: Blackwell), 145-181.

Khayet, M., and Fernández, V. (2012). Estimation of the solubility parameters of model plant surfaces and agrochemicals: a valuable tool for understanding plant surface interactions. Theor. Biol. Med. Model. 9:45. doi: 10.1186/17424682-9-45

Koch, K., Neinhuis, C., Ensikat, H. J., and Barthlott, W. (2004). Self assembly of epicuticular waxes on living plant surfaces imaged by atomic force microscopy (AFM). J. Exp. Bot. 55, 711-718. doi: 10.1093/jxb/erh077

Kolattukudy, P. E. (1970). Biosynthesis of a lipid polymer, cutin: the structural component of plant cuticle. Biochem. Biophys. Res. Commun. 41, 299-305. doi: 10.1016/0006-291X(70)90503-6

Kolattukudy, P. E. (1980). Biopolyester membranes of plants: cutin and suberin. Science 208, 990-1000. doi: 10.1126/science.208.4447.990

Kunst, L., and Samuels, L. (2009). Plant cuticles shine: advances in wax biosynthesis and export. Curr. Opin. Plant Biol. 12, 721-727. doi: 10.1016/j.pbi.2009. 09.009

Kutschera, U. (2008). The growing outer epidermal wall: design and physiological role of a composite structure. Ann. Bot. 101, 615-621. doi: 10.1093/aob/mcn015 Kutschera, U., and Niklas, K. J. (2007). The epidermal-growth-control theory of stem elongation: an old and a new perspective. J. Plant Physiol. 164, 1395-1409. doi: 10.1016/j.jplph.2007.08.002

Li, H., Madden, J. L., and Potts, B. M. (1997). Variation in leaf waxes of the Tasmanian Eucalyptus species - I. Subgenus symphyomyrtus. Biochem. Syst. Ecol. 25, 631657. doi: 10.1016/S0305-1978(97)00044-6

López-Casado, G., Matas, A. J., Domínguez, E., Cuartero, J., and Heredia, A. (2007). Biomechanics of isolated tomato (Solanum lycopersicum L.) fruit cuticles: the role of the cutin matrix and polysaccharides. J. Exp. Bot. 58, 3875-3883. doi: 10.1093/jxb/erm 233 
Matas, A. J., Cobb, E. D., Bartsch, J. A., Paolillo, D. J., and Niklas, K. J. (2004). Biomechanics and anatomy of Lycopersicon esculentum fruit peels and enzymetreated samples. Am. J. Bot. 91, 352-360. doi: 10.3732/ajb.91.3.352

Oladele, F. A. (1983). Inner surface sculpture patterns of cuticles in Cupressaceae. Can. J. Bot. 61, 1222-1231. doi: 10.1139/b83-130

Pollard, M., Beisson, F., Li, Y., and Ohlrogge, J. B. (2008). Building lipid barriers: biosynthesis of cutin and suberin. Trends Plant Sci. 13, 236-246. doi: 10.1016/j.tplants.2008.03.003

Remus-Emsermann, M. N. P., de Oliveira, S., Schreiber, L., and Leveau, J. H. (2011). Quantification of lateral heterogeneity in carbohydrate permeability of isolated plant leaf cuticles. Front. Microbiol. 2:197. doi: 10.3389/fmicb.2011. 00197

Riedel, M., Eichner, A., Meimberg, H., and Jetter, R. (2007). Chemical composition of epicuticular wax crystals on the slippery zone in pitchers of five Nepenthes species and hybrids. Planta 225, 1517-1534. doi: 10.1007/s00425-0060437-3

Riederer, M., and Schönherr, J. (1988). Development of plant cuticles: fine structure and cutin composition of Clivia miniata. Reg. leaves. Planta 174, 127-138. doi: 10.1007/BF00394885

Roland, J. C., Reis, D., Mosiniak, M., and Vian, B. (1982). Cell wall texture along the growth gradient of the mung bean hypocotyl: ordered assembly and dissipative processes. J. Cell Sci. 56, 303-318.

Samuels, L., Kunst, L., and Jetter, R. (2008). Sealing plant surfaces: cuticular wax formation by epidermal cells. Annu. Rev. Plant Biol. 59, 683-707. doi 10.1146/annurev.arplant.59.103006.093219

Schmidt, H. W., and Schönherr, J. (1982). Development of plant cuticles: occurrence and role of non-ester bonds in cutin of Clivia miniata Reg. leaves. Planta 156 380-384. doi: 10.1007/BF00397478

Serrano, M., Coluccia, F., Torres, M., L'Haridon, F., and Métraux, J. P. (2014). The cuticle and plant defense to pathogens. Front. Plant Sci. 5:274. doi: 10.3389/fpls.2014.00274

Silvestre, A. J. D., Cavaleiro, J. A. S., Delmond, B., Filliatre, C., and Bourgeois, G. (1997). Analysis of the variation of the essential oil composition of Eucalyptus globulus Labill. from Portugal using multivariate statistical analysis. Ind. Crops Prod. 6, 27-33. doi: 10.1016/S0926-6690(96)00200-2

Steinbauer, M. J., Davies, N. W., Gaertner, C., and Derridj, S. (2009). Epicuticular waxes and plant primary metabolites on the surfaces of juvenile Eucalyptus globulus and E. nitens (Myrtaceae) leaves. Aust. J. Bot. 57, 474-485. doi: 10.1071/BT09108

Takada, S., and Iida, H. (2014). Specification of epidermal cell fate in plant shoots. Front. Plant Sci. 5:49. doi: 10.3389/fpls.2014.00049

Tegelaar, E. W., Kerp, H., Visscher, H., Schenck, P. A., and de Leeuw, J. W. (1991). Bias of the paleobotanical record as a consequence of variations in the chemical composition of higher vascular plant cuticles. Paleobiology 17, 133-144.
Tsubaki, S., Sugimura, K., Teramoto, Y., Yonemori, K., and Azuma, J. I. (2013) Cuticular membrane of Fuyu Persimmon fruit is strengthened by triterpenoid nano-fillers. PLoS ONE 8:e75275. doi: 10.1371/journal.pone.0075275

Tyree, M. T., Scherbatskoy, T. D., and Tabor, C. A. (1990). Leaf cuticles behave as asymmetric membranes: evidence from the measurement of diffusion potentials. Plant Physiol. 92, 103-109. doi: 10.1104/pp.92.1.103

Verdeguer, M., Blázquez, M. A., and Boira, H. (2009). Phytotoxic effects of Lantana camara, Eucalyptus camaldulensis and Eriocephalus africanus essential oils in weeds of Mediterranean summer crops. Biochem. Syst. Ecol. 37, 362-369. doi: 10.1016/j.bse.2009.06.003

Viougeas, M. A., Rohr, R., and Chamel, A. (1995). Structural changes and permeability of ivy (Hedera helix L.) leaf cuticles in relation to leaf development and after selective chemical treatments. New Phytol. 130, 337-348. doi: 10.1111/j.1469-8137.1995.tb01828.x

von Mohl, H. (1847). Untersuchungen der Frage: bildet die Cellulose die Grundlage sammtlicher Vegetabilischen Membranen. Bot. Zeitung 5, 497-505.

Wattendorff, J., and Holloway, P. J. (1982). Studies on the ultrastructure and histochemistry of plant cuticles: isolated cuticular membrane preparations of Agave americana L. and the effects of various extraction procedures. Ann. Bot. 49, 769-804.

Yeats, T. H., Buda, G. J., Wang, Z., Chehanovsky, N., Moyle, L. C., Jetter, R., et al. (2012). The fruit cuticles of wild tomato species exhibit architectural and chemical diversity, providing a new model for studying the evolution of cuticle function. Plant J. 69, 655-666. doi: 10.1111/j.1365-313X.2011.04820.x

Yeats, T. H., and Rose, J. K. (2013). The formation and function of plant cuticles. Plant Physiol. 163, 5-20. doi: 10.1104/pp.113.222737

Conflict of Interest Statement: The authors declare that the research was conducted in the absence of any commercial or financial relationships that could be construed as a potential conflict of interest.

Received: 02 July 2014; accepted: 30 August 2014; published online: 16 September 2014. Citation: Guzmán P, Fernández V, Graça J, Cabral V, Kayali N, Khayet M and Gil $L$ (2014) Chemical and structural analysis of Eucalyptus globulus and E. camaldulensis leaf cuticles: a lipidized cell wall region. Front. Plant Sci. 5:481. doi: 10.3389/fpls.2014.00481

This article was submitted to Plant Cell Biology, a section of the journal Frontiers in Plant Science.

Copyright (C) 2014 Guzmán, Fernández, Graça, Cabral, Kayali, Khayet and Gil. This is an open-access article distributed under the terms of the Creative Commons Attribution License (CC BY). The use, distribution or reproduction in other forums is permitted, provided the original author(s) or licensor are credited and that the original publication in this journal is cited, in accordance with accepted academic practice. No use, distribution or reproduction is permitted which does not comply with these terms. 